\title{
OPTIMASI BIAYA PELAKSANAAN KONSTRUKSI JALAN DENGAN APLIKASI REKAYASA NILAI (VALUE ENGINEERING)
}

\author{
Astiah Amir1, Zakia2 \\ 1)2) Dosen Jurusan Teknik Sipil, Fakultas Teknik, Universitas Teuku Umar \\ email: asti_mks@yahoo.co.id
}

\begin{abstract}
Abstrak
Penelitian ini dilakukan untuk optimalisasi biaya pelaksanaan konstruksi jalan dengan aplikasi metode rekayasa nilai (value engineering). Objek yang dikaji adalah Project Package JNB1 of Road: Lueng Gayo - Arongan Lambalek pada STA 198 - STA 216 Kabupaten Aceh Barat Provinsi Aceh. Fungsi jalan ini merupakan infrastruktur penghubung antara Banda Aceh dengan Meulaboh. Dalam metode Rekayasa Nilai terdapat beberapa tahapan yang harus dilakukan yaitu tahap informasi, tahap kreatif, tahap analisa, dan tahap rekomendasi. Hasil kajian menunjukkan bahwa komponen pekerjaan yang layak diadakan aplikasi rekayasa nilai adalah selected embankment dan asphalt yang merupakan wilayah studi. Kedua division ini dianalisis fungsi dan layak untuk diadakan rekayasa nilai. Hasil analisis menunjukkan bahwa alternatif Vertical Vibre Drain (VVD) dan Horizontal Sand Drain (HSD), Cakar ayam Modifikasi (CAM) yang menjadi ide kreatif berdasarkan brainstorming, setelah diadakan rekayasa nilai memiliki keunggulan dibandingkan alternatif existing (Geotextile dan geogrid kombinasi cerucuk), dengan melihat kriteria mutu konstruksi, biaya pemeliharaan, ramah lingkungan dan Life Cycle Cost (LCC). LCC untuk alternatif pemancangan VVD dan HSD Rp. 120.865.300.964, alternatif CAM adalah Rp.115.639.315.748,61.; dibandingkan dengan life cycle cost (LCC) existing (Geotextile dan geogrid kombinasi cerucuk) sebesar Rp. 128.487.519.598. Besar penghematan biaya (cost saving) setelah dilakukan Rekayasa Nilai (Value Engineering) adalah sebesar Rp.12.848.203.849,39 atau 10\% untuk pelaksanaan konstruksi dengan metode dan teknologi konstruksi CAM sebagai alternatif terpilih.
\end{abstract}

Kata Kunci : Rekayasa Nilai, Optimalisasi, Biaya konstruksi, Jalan.

\begin{abstract}
This study was conducted to optimize the construction cost the road with the application of Value engineering methods. Object studied is JNB1 of Road Project Package: Lueng Gayo - Arongan Lambalek at STA 198 - STA 216 West Aceh district of Aceh province. The function of This road infrastructure liaison between Banda Aceh to Meulaboh. In the Value Engineering method content of several steps that must be done, the steps are stage of information, creative phase, analysis phase, and recommendation phase. The result showed that the qcomponents of decent work held engineering application value is selected embankment and asphalt. Developed alternative assessment results for further analysis through Value Engineering work steps. The results show that alternative Vertical Vibre Drain (VVD) and Horizontal Sand Drain (HSD), chicken claws Modification (CAM) is a creative idea by brainstorming, after allowing for value engineering has advantages over existing alternatives (Geotextile and geogrid combination of wooden stakes), by looking at the criteria of quality of construction, maintenance cost, and environmentally friendly, and Life Cycle cost (LCC). LCC for alternative erection VVD and HSD Rp. 120,865,300,964, CAM alternative is Rp.115,639,315,748.61.; compared with the life cycle cost (LCC) existing (Geotextile and geogrid of combination of wooden stakes 128,487,519,598. Large cost savings after implementing Value Engineering is Rp.12, 848,203,849.39 or 10\% of the construction methods and construction technology CAM as the selected alternative.
\end{abstract}

Keywords: Value Engineering, Optimization, Construction Cost, Road 


\section{PENDAHULUAN}

Pada saat ini pemerintah telah mencanangkan percepatan pembangunan infrastruktur dalam rangka pertumbuhan ekonomi. Sementara itu, dana pemerintah yang tersedia sangat terbatas sehingga diperlukan penghematan dan efisiensi biaya. Pekerjaan infrastruktur transportasi merupakan salah satu pekerjaan yang seringkali menggunakan anggaran yang sangat besar. Proyek dalam penggunaan dana yang besar, memungkinkan terjadi inefisiensi anggaran. Di Provinsi Aceh, salah satu yang termasuk dalam pekerjaan semacam ini adalah proyek jalan lintas Banda Aceh Meulaboh. Pekerjaan ini diperkirakan akan menggunakan anggaran sebesar Rp.93.069.528.000,- untuk penanganan jalan sepanjang $18 \mathrm{Km}$.

Merujuk pada Peraturan Menteri Pekerjaan Umum (Permen PU) Nomor 06/PRT/M/2008 tentang pedoman pengawasan penyelenggaraan dan pelaksanaan pemeriksaan konstruksi di lingkungan Kementerian PU, apabila dalam pemeriksaan ditemukan adanya inefisiensi, maka direkomendasikan kepada pengguna jasa untuk menerapkan metode Value Engineering (VE).

Tujuan dan manfaat yang diinginkan dari penelitian ini adalah untuk mengidentifikasii komponen pekerjaan yang berpotensi untuk diadakan rekayasa nilai (value engineering) yang menjadi wilayah studi rekayasa nilai, menentukan alternatif usulan yang dapat dilakukan untuk diadakan rekayasa nilai (value engineering) yang dapat memberikan optimasi biaya dan mengetahui besar penghematan biaya pelaksanaan (Cost saving) setelah dilakukan aplikasi Rekayasa Nilai (Value Engineering).

Saptono (2008), menganalisis tentang value engineering terhadap model bangunan atas jembatan, Berdasarkan analisis kelayakan dan untung rugi terpilih jembatan komposit baja beton yang memenuhi syarat kekuatan dengan biaya optimal. Ikhsan ( 2011), dalam penelitiannya tentang struktur rangka bangunan dan penghematan biaya dengan menggunakan rekayasa Nilai dengan menganalisis ulang mengenai fungsi terhadap kolom dan balok dengan menggunakan struktur Staggered Truss systems. Dari hasil penerapan Rekayasa nilai Penggunaan Staggered Truss systems dibandingkan dengan struktur open frame adalah biaya tak berguna pelaksanaan konstruksi open frame dan struktur Staggered Truss systems sebesar Rp.1.568.233.093,9,- atau 27,45\%. Perbedaan dengan penelitian - penelitian yang di atas adalah terletak pada 'subjek penelitian. Dalam penelitian ini akan dilakukan optimasi biaya pelaksanaan konstruksi jalan dengan aplikasi Rekayasa Nilai (Value Engineering).

\section{METODE PENELITIAN}

Tahapan pemecahan masalah dengan aplikasi Rencana Kerja Rekayasa Nilai (Value Engineering) diawali dengan pengenalan daerah studi, pengumpulan data, menganalisis fungsi, 
evaluasi aspek teknis, analisis kelebihan dan kerugian, kelayakan pemanfaatan. 


\section{Metode Pengumpulan Data}

Setelah pemilihan objek dan subjek serta perumusan masalah ditetapkan sebagai salah satu bagian dari tahap informasi, selanjutnya dilakukan pengumpulan data yang diperlukan.

\section{Jenis Data}

Data yang digunakan dalam penelitian ini adalah data primer dan data sekunder yaitu :

a. Data Primer

Data primer adalah data yang didapatkan melalui pengamatan langsung, wawancara dengan pihak terkait atau hasil penelitian terhadap suatu objek, yang termasuk katagori data primer adalah :

- Letak titik STA yang menggunakan geotextile dan geogrid;

- $\quad$ Kedalaman gambut pada existing yang melintasi lahan gambut mencapai \pm 7 meter.

b. Data Sekunder

Data sekunder adalah data yang didapatkan secara tidak langsung melalui media perantara (diperoleh dan dicatat oleh pihak lain). Data sekunder sebagai pedoman pemilihan alternatif yang akan direkomendasikan sebagai hasil dari rekayasa nilai yang memberikan biaya yang optimal.

\section{Teknik Pengumpulan Data}

Dalam melakukan penulisan penelitian ini, penulis mengumpulkan data dengan cara :

1. Metode Pengambilan Data Primer

Melakukan survey langsung, dan menyebarkan kuisiner untuk menentukan rangking kriteria menggunakan skala likert sebagai acuan untuk menentukan alternatif terbaik, yang melibatkan pihak akademisi dan praktisi serta wawancara dengan pihak terkait pada pelaksana yang menangani proyek yang menjadi objek penelitian.

2. Metode Pengambilan Data Sekunder

Mendapatkan data dengan cara mengumpulkan, mengidentifikasi, mengolah data tertulis dan metode kerja yang digunakan.

\section{Peralatan Pengolahan Data}

Alat yang digunakan dalam pengolahan data pada penelitian ini adalah alat - alat analisis kelebihan dan kekurangan, dan kelayakan pemanfaatan.

\section{Proses Pengolahan Data}

Pengolahan data dilakukan dengan menerapkan metode rencana kerja rekayasa nilai sebagai berikut :

1. Tahap Informasi (information Phase)

Pada tahap ini, langkah-langkah yang perlu dilakukan adalah :

a. Mengumpulkan informasi yang berhubungan dengan objek penelitian. Mengkaji permasalahan permasalahan pada objek penelitian. Proyek ini didanai oleh Multi Donor Trust Fund For Aceh and North Sumatra (MDF) Grant TF : 098082. Untuk bunga dana pinjaman kepada pemerintah Indonesia $0 \%$ untuk masa sepuluh tahun, 2,5\% untuk tahu ke 11-20 dan 5\% untuk tahun ke 21 35. (http://web.worldbank.org). 
b. Menentukan sasaran studi

Pengurutan item pekerjaan yang memiliki biaya tertinggi pada tabel Cost Breakdown dengan grafik hukum distribusi Pareto, kemudian ditemukan pekerjaan yang akan direkayasa nilai sehingga akan diperoleh besarnya perbandingan antara cost/worth., dengan FAST akan menghasilkan fungsi primer dan sekunder yang akan menunjukkan layak atau tidaknya diadakan Rekayasa Nilai $(V E)$

\section{Tahap kreatif ( creative phase)}

Pada tahap ini dilakukan pengembangan terhadap sejumlah alternatif yang ada. Pertimbangannya adalah alternatif yang sesuai dengan kondisi pada proyek yang ditinjau.

3. Tahap analisis (Analysis phase).

Analisa pemilihan alternatif merupakan analisa terakhir yang dilakukan dalam rangkaian rencana kerja rekayasa nilai, langkah yang akan ditempuh dalam aplikasi Rekayasa Nilai. Tahapan tersebut adalah :

a. Penentuan kriteria penilaian

b. Analisis Kelebihan dan Kekurangan

Dari hasil pemilihan prioritas kriteria yang dihasilkan dari responden selanjutnya dapat ditentukan perangkingan perioritas kriteria.

$$
\text { Pembobotan }=\frac{\text { Angka rangking yang dimiliki }}{\text { Jumlah angka rangking }} \times 100 \%
$$

Setelah diketahui bobot, dilakukan analisa Zero - One c. Analisis Kelayakan Manfaat

Pada proses ini akan dianalisis kelayakan pemanfaatan pada waktu yang akan datang. Teknik yang digunakan adalah analisis manfaat biaya, yang dikenal dengan teknik life cycle costing.

\section{TahapRekomendasi (Recommendation phase)}

Tahap ini merupakan tahap akhir dari Rencana Kerja Rekayasa Nilai yang sering disebut tahap pengembangan dan penyajian. Pada tahap ini direkomendasikan hasil penerapan Rekayasa Nilai oleh semua manajemen proyek .

\section{HASIL DAN PEMBAHASAN}

Penyajian hasil pengolahan data terhadap objek yang menjadi tinjauan, dilakukan sesuai langkah kerja

Rekayasa Nilai (Value Engineering) :

\section{Tahap Informasi (Information Phase)}

Tahap informasi memberikan gambaran secara lengkap atas objek studi, yang menjadi dasar untuk melakukan seleksi dalam memilih wilayah studi dengan identifikasi fungsi dan estimasi biaya yang mendasar pada fungsi pokok.

Tabel 2 tabel Cost Breakdown. Item pekerjaan yang memiliki bobot biaya tertinggi dan berdasar distribusi Pareto dipilih untuk selanjutnya dianalisis fungsi adalah pekerjaan asphalt pavement dan 
earthworks. Komponen pekerjaan berbiaya tinggi adalah selected embankment, Asphalt Concreete Wearing Course (AC-WC) dan Asphalt Binder Course (AC-BC) yang mmerupakan wilayah studi.

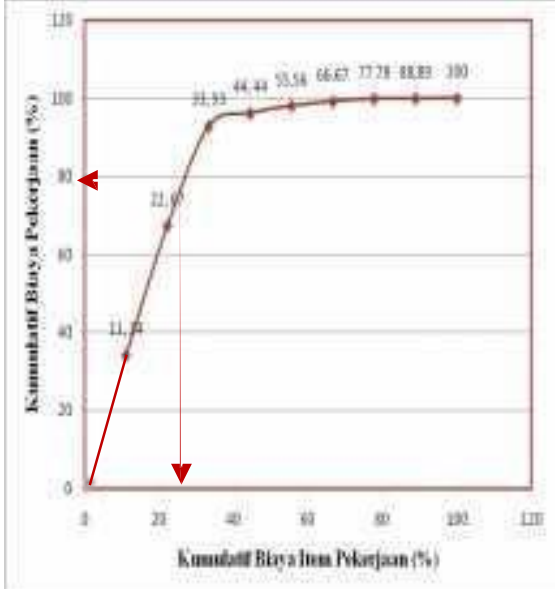

Gambar 1 Distribusi Pareto Division asphalt dan Earthwork

Tabel 2 Identifikasi Item Pekerjaan Berbiaya Tinggi

\begin{tabular}{|c|c|c|c|c|c|}
\hline 1 & Asphalt Pavement & $31.031 .240 .096,25$ & 33,34 & 33,34 & 8,33 \\
\hline 2 & Earthworks & 16. $668.717 .818,22$ & 17,91 & 51,252 & 16,67 \\
\hline 3 & Structures & 13. $867.568 .416,91$ & 14,90 & 66,152 & 25,00 \\
\hline 4 & Granular Pavement & 1.865 .217 .825 & 11,674 & 77,83 & 33,33 \\
\hline 5 & Pavement widening \& sholders & 7.875 .160 .020 & 8,462 & 86,29 & 41,67 \\
\hline 6 & General & 1.933 .430 .500 & 2.077 & 88,365 & 50,00 \\
\hline 7 & Reinstatement and minor works & 1. $106.804 .272,64$ & 11,892 & 89,554 & 58,33 \\
\hline 8 & Drainage & 592. 197.613,48 & 0,6363 & 90,191 & 66,67 \\
\hline 9 & Day Work & $48.325 .708,84$ & 0,0519 & 902,429 & 75,00 \\
\hline $\begin{array}{l}10 \\
\text { (A) }\end{array}$ & Sum of Division 1 to 10 & 83. 988.662.271,34 & & & \\
\hline B1) & Provisional Sum for EMC Works & 500.000 .000 & & 90,78 & 83,3 \\
\hline & l Action Plan, Environmental Ag & 120.000 .000 & 0,12894 & 90,909 & 91,67 \\
\hline (C) & $\begin{array}{l}\text { Value Added Taxes }(100 \times A \\
+B 1+B 2)\end{array}$ & $8.460 .866 .227,134$ & 9,091 & 100 & 100 \\
\hline (D) & $\begin{array}{l}\text { Total Bid Price }=(A+B 1+B 2) \\
+(C))\end{array}$ & 93. 069. 528.498,474 & & & \\
\hline (E) & & Rounded & & & \\
\hline & Total Price & 93.069 .528 .000 & 100 & 100 & \\
\hline
\end{tabular}

Tabel 3 Analisis Fungsi Pekerjaan Asphalt

\begin{tabular}{|c|c|c|c|c|c|c|}
\hline \multicolumn{7}{|c|}{ Tahap Informasi } \\
\hline \multicolumn{7}{|c|}{ Ana lisa Fungsi } \\
\hline \multirow{3}{*}{$\begin{array}{l}\text { Item } \\
\text { No }\end{array}$} & Pekerjaan: & Asphalt Pave & nent & & \multirow{3}{*}{ Cost } & \multirow{3}{*}{ Worth } \\
\hline & \multirow{2}{*}{ Komponen } & \multicolumn{3}{|c|}{ Fungsi } & & \\
\hline & & Kata kerja & Kata Benda & Jenis & & \\
\hline 1 & Tack Coat & Mengikat & Elemen & $S$ & $1.577 .066 .732,5$ & \\
\hline 2 & Prime Coat & Meresapkan & Elemen & $\mathrm{S}$ & $908.899 .623,75$ & \\
\hline \multirow[t]{2}{*}{3} & $A C-W C$ & Menahan & Beban & B & 15.841 .494 .000 & 15.841 .494 .000 \\
\hline & $A C-B C$ & Menyalurkan & Beban & & 12.169 .447 .200 & \\
\hline \multirow[t]{3}{*}{4} & $A C-B C$ levelin $g$ & Menambah & Elemen & S & 534.332 .540 & \\
\hline & \multicolumn{4}{|c|}{ Total } & - & 15.841 .494 .000 \\
\hline & & & \multicolumn{2}{|c|}{ Cost $/$ Worth $=$} & 1,959 & \\
\hline
\end{tabular}

Tabel 4 Analisa Fungsi Pekerjaan Earthworks

\begin{tabular}{|c|c|c|c|c|c|c|}
\hline \multicolumn{7}{|c|}{ Tahap Informasi } \\
\hline \multicolumn{7}{|c|}{ Analisa Fungsi } \\
\hline \multicolumn{2}{|c|}{ Item Pekerjaan : } & Earth Works & & & \multirow{3}{*}{ Cost } & \multirow{3}{*}{ Worth } \\
\hline \multirow{2}{*}{ No } & \multirow{2}{*}{ Komponen } & \multicolumn{3}{|c|}{ Fungsi } & & \\
\hline & & Kata kerja & Kata Benda & Jenis & & \\
\hline 1 & Common excav ation & $\begin{array}{l}\text { Mengganti } \\
\text { material } \\
\text { existing }\end{array}$ & Subgrade & $S$ & 337.518 .239 & \\
\hline 2 & $\begin{array}{l}\text { Material without } \\
\text { Milling }\end{array}$ & Mengganti & Subgrade & $\mathrm{S}$ & 31.586 .329 & \\
\hline 3 & Selected embankment & Menahan & Subgrade & B & 16.283 .960 .000 & 9.941 .337 .071 \\
\hline \multirow[t]{3}{*}{4} & Garade Preparation & Mengganti & Subgrade & $S$ & 15.671 .250 & \\
\hline & \multicolumn{4}{|c|}{ Total } & 15.671 .250 & 9.941 .337 .071 \\
\hline & & & \multicolumn{2}{|c|}{ Cost $/$ Wort $h=$} & 1,667 & \\
\hline
\end{tabular}


Universitas Teuku Umar

Berdasarkn Tabel 3, dan Tabel 4, dapat dilihat bahwa komponen embankment dari division asphalt yang

menjalankan fungsi dasar (basic.). Besarnya cost/worth untuk pekerjanan asphalt adalah 1.95 dan earthwork

adalah 1.677 lebih besar dari 1(satu) yang berarti akan ada penghematan biaya (cost Saving) dan layak untuk diadakan aplikasi Rekayasa Nilai (Value Engineering).

\section{Tahap Kreatif (Creative Phase)}

Hasil kajian pada tahap informasi menunjukkan, bahwa pekerjaan yang memiliki biaya yang paling tinggi adalah embankment dan Asphalt . Pekerjaan ini mempunyai cost/worth lebih dari 1 (satu) sehingga layak untuk dilakukan aplikasi Rekayasa Nilai (value Engineering).Sebagai bagian dari tahap kreatif, dikemukakan beberapa alternatif teknologi konstruksi jalan untuk optimalisasi biaya dengan Wilayah studi pekerjaan embankment dan Asphalt dapat dilihat pada Tabel 5. Untuk optimalisasi biaya pada penelitian ini dari pengumpulan alternatif yang akan digunakan ditentukan berdasarkan hasil dari brainstorming berupa pendapat dari para ahli konstruksi jalan yang dianggap mengerti dan ahli dalam hal ini dan hasilnya dipilih 2 (dua) usulan yang dianggap sesuai dengan lokasi dan karakteristik jalan yang menjadi tinjauan studi kasus penelitian adalah :

a. Pemancangan Vertical Vibre Drain (VVD) dan Horizontal Sand Drain

b. Cakar Ayam Modifikasi (CAM)

\section{Tahap Analisi (Analyis Phase)}

Tahap analisis merupakan langkah untuk menentukan alternatif terbaik melalui penerapan aplikasi Rekayasa Nilai (Value Engineering). Tahapan tersebu terdiri atas :

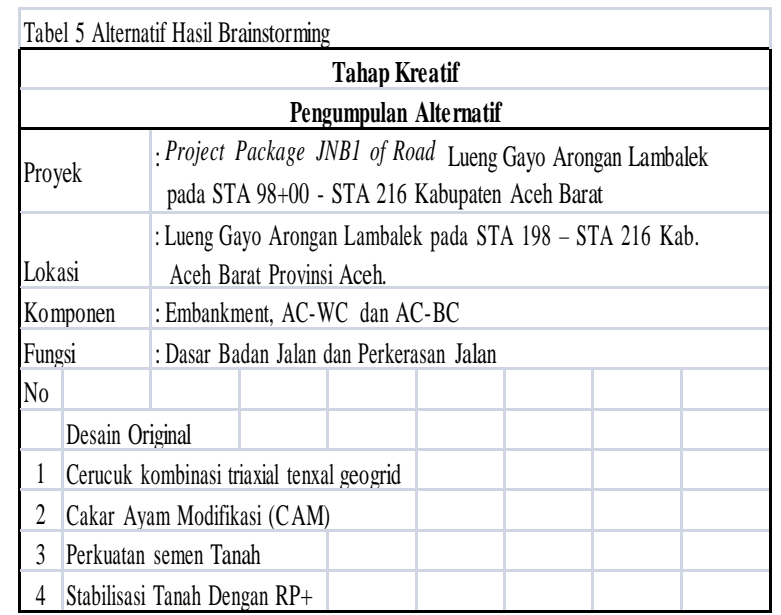

\begin{tabular}{|c|c|c|c|c|}
\hline No & Metode Kons truksi & STA & Panjang & Satuan \\
\hline \multirow[t]{2}{*}{ I } & $\begin{array}{l}\text { Pemancangan VVD dan HSD } \\
\text { dikombinasi dengan Geomembran }\end{array}$ & $\begin{array}{c}02+075-4+800 \\
01+000-02+075 \\
\text { DAN } 04+800- \\
08+950\end{array}$ & 7.950 & $\mathrm{Km}$ \\
\hline & Mengeliminasi Geotextile & $\begin{array}{c}0.00-950 \\
\text { dan13+000- } \\
17+900\end{array}$ & 5.850 & $\mathrm{Km}$ \\
\hline \multirow{2}{*}{ II } & $\begin{array}{l}\text { Cakar Ayam Modifikasi (CAM) dan } \\
\text { mengeliminasi geogrid pada STA } 0.00- \\
0+950 \text { dan STA } 13+000-\text { STA } 17+900\end{array}$ & $\begin{array}{c}02+075- \\
4+800,01+000- \\
02+075 \text { dan } \\
04+800-08+950\end{array}$ & 7.950 & $\mathrm{Km}$ \\
\hline & Mengeliminasi Geotextile & $\begin{array}{c}0.00-950 \\
\text { dan13+000- } \\
17+900\end{array}$ & 5.850 & $\mathrm{Km}$ \\
\hline
\end{tabular}

a. Penentuan kriteria penilaian

b. Analisis Kelebihan dan Kekurangan

Analisis kelebihan dan kekurangan menggunakan analisis Zero one. Dari hasil pemilihan prioritas kriteria yang dihasilkan dari responden dapat ditentukan bobot perioritas kriteria. Untuk menentukan bobot kriteria dipilih rangking 1 sampai 9 dapat dilihat pada Tabel 7 : 
Tabel 7 Prírias Krieria Penilaian

\begin{tabular}{|r|l|c|c|c|}
\hline No & \multicolumn{1}{|c|}{ Fungsi } & Angka Rangking & Bobot (\%) & Keterangan \\
\hline 1 & $\begin{array}{l}\text { Mutu konstruksi yang } \\
\text { dihasilkan }\end{array}$ & 9 & 20 & \\
2 & Biaya awal & 8 & 17,8 & \\
\hline 3 & Biaya pemeliharaan & 7 & 15,6 & \\
\hline 4 & Kemudahan pelaksanaan & 6 & 13,3 & \\
\hline 5 & Umur rencana & 5 & 11,1 & \\
\hline 6 & Ramah lingkungan & 4 & 8,9 & \\
\hline 7 & teknologi & 3 & 6,7 & \\
8 & Waktu pemesanan & 2 & 4,4 & \\
\hline 9 & Teknologi & 1 & 2,2 & \\
\hline & Jumlah & 45 & 100 & \\
\hline
\end{tabular}

Konstruksi Jalan Yang menjadi alternatif dapat dilihatbpada Gambar 2 :

\section{Geotextile dan Geogrid (Existing)}

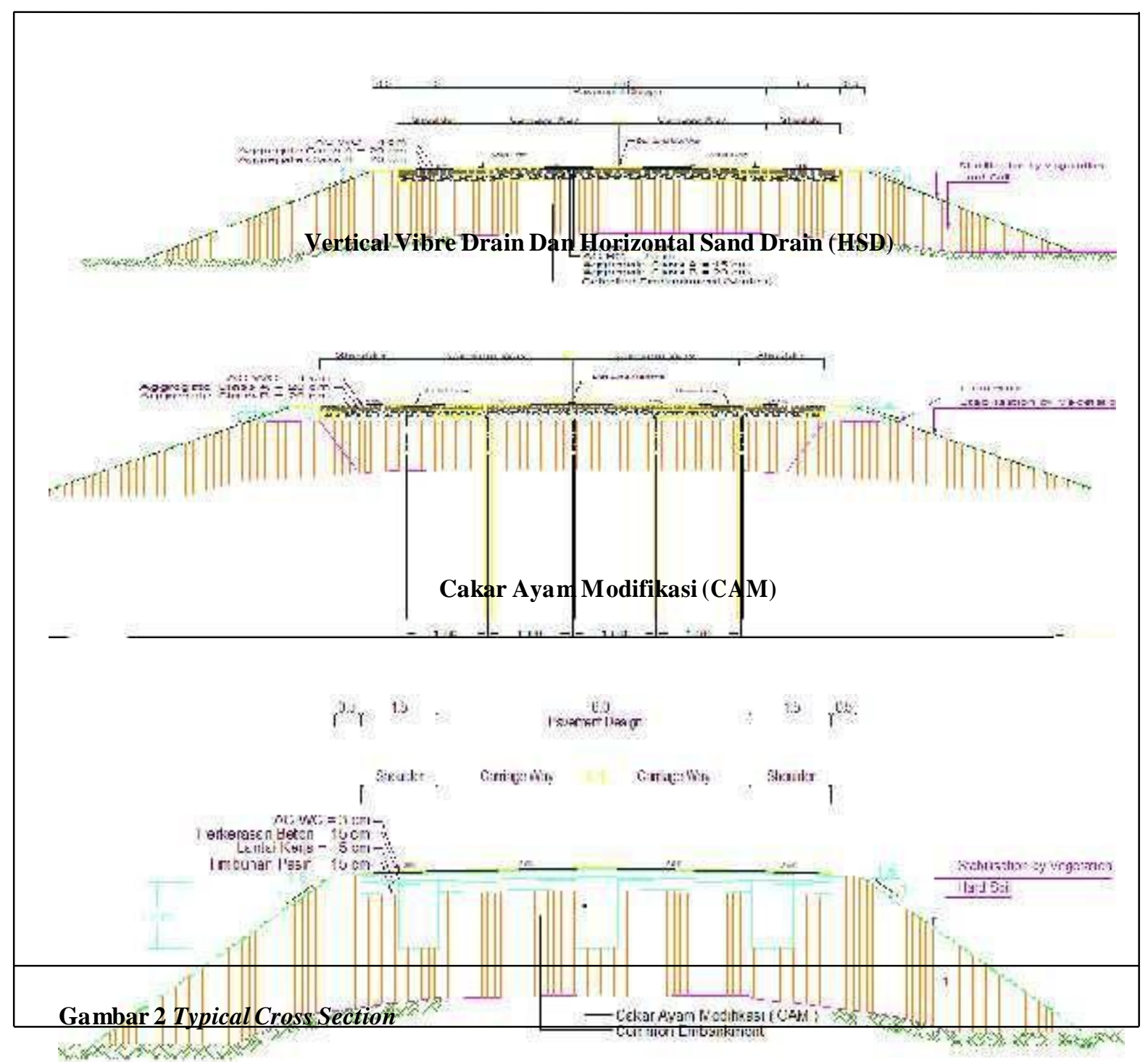


Tabel 8 Tabel Matriks Evaluasi Zero One

\begin{tabular}{|c|c|c|c|c|c|c|c|c|c|c|c|}
\hline \multirow{3}{*}{ NO } & \multirow{3}{*}{ Altern ative } & \multicolumn{9}{|c|}{ As ses sment Criteria } & \multirow{3}{*}{ Total } \\
\hline & & A & B & $\mathrm{C}$ & D & $\mathrm{E}$ & $\mathrm{F}$ & $\mathrm{G}$ & $\mathrm{H}$ & I & \\
\hline & & 20 & 17.8 & 15,6 & 13,3 & 11.1 & 8,9 & 6,7 & 4,4 & 2,2 & \\
\hline \multirow{2}{*}{1} & \multirow{2}{*}{$\begin{array}{l}\text { Alternativ e I } \\
\text { (Existing) }\end{array}$} & 0 & $1 / 1$ & $1 / 2$ & $1 / 2$ & $1 / 2$ & 0 & $1 / 2$ & $1 / 2$ & 0 & \\
\hline & & 0 & 17.8 & 7,8 & 6,66 & 5.55 & 0 & 3,35 & 2,2 & 0 & 43,36 \\
\hline \multirow{2}{*}{2} & \multirow{2}{*}{$\begin{array}{l}\text { Altern ative II } \\
\text { WDD dan HSD }\end{array}$} & $1 / 1$ & 0 & $1 / 2$ & $1 / 2$ & $1 / 2$ & $1 / 1$ & $1 / 2$ & $1 / 2$ & $1 / 1$ & \\
\hline & & 20 & 0 & 7,8 & 6,66 & 5.55 & 8,9 & 3,35 & 2,2 & 2,2 & 56,66 \\
\hline \multirow{2}{*}{3} & \multirow{2}{*}{$\begin{array}{c}\text { Alternat if I } \\
\text { (Existing) }\end{array}$} & 0 & $1 / 1$ & 0 & $1 / 2$ & $1 / 2$ & 0 & $1 / 2$ & $1 / 2$ & 0 & \\
\hline & & 0 & 17.8 & 0 & 6,66 & 5.55 & 0 & 3,35 & 2,2 & 0 & 35,56 \\
\hline \multirow{2}{*}{4} & \multirow{2}{*}{$\begin{array}{c}\text { A ltern ative III } \\
\text { CAM }\end{array}$} & $1 / 1$ & 0 & $1 / 1$ & $1 / 2$ & $1 / 2$ & $1 / 1$ & $1 / 2$ & $1 / 2$ & $1 / 1$ & \\
\hline & & 20 & 0 & 15,6 & 6,66 & 5.55 & 8,9 & 3,35 & 2,2 & 2,2 & 64,46 \\
\hline
\end{tabular}

Keterangan :

A. Mutu konstruksi

B. Biaya awal

C. Biaya Pemeliharaan

D. Kemudahan Pelaksanaan

E. Umur Rencana

F. Ramah lingkungan

G. Waktu pelaksanaan

H.Waktu pemesanan

I. Teknologi

\section{c. Analisis Kelayakan Manfaat}

Metode yang akan digunakan adalah Analisis manfaat biaya, dengan teknik analisis life cycle costing . Dapat dilihat pada Tabel 9 dan Tabel 10 :

Tabel 9 Biaya Pemeliharaan dan Penggantian Maintenance and Replacement)

\begin{tabular}{|c|l|c|c|c|}
\hline No & \multicolumn{1}{|c|}{ AnalisaBiaya } & VVDdan HSD & CAM & Geotextile dan geogrid \\
\hline 1 & Biaya awal & 96.243 .462 .000 & 94.091 .037 .000 & 93.069 .528 .000 \\
2 & W aktu pemeliharaan & 15 tahun & 15 tahun & 15 tahun \\
\hline 3 & Tingkat suku bunga & $\begin{array}{c}\text { tahun O-10 (0\%), 11- } \\
20(2.5 \%)\end{array}$ & $\begin{array}{c}\text { tahun 0-10 (0\%), 11-20 } \\
(2.5 \%)\end{array}$ & $\begin{array}{c}\text { tahun O-10 (0\%), 11- } \\
20(2.5 \%)\end{array}$ \\
\hline 4 & Annual Pemeliharaan & 2.607 .515 .970 & 2.032 .072 .361 & 3.584 .183 .652 \\
\hline
\end{tabular}

Tabel 10 Hasil Perhitungan Biaya Siklus Hidup (life CycleCostO

\begin{tabular}{|r|l|r|r|r|}
\hline \multirow{2}{*}{ No } & \multicolumn{2}{|c|}{ Biaya } & \multicolumn{2}{|c|}{ Alternatif } \\
\cline { 3 - 5 } & & \multicolumn{1}{|c|}{ VVD dan HSD } & \multicolumn{1}{c|}{ CAM } & Geotextile dan geogrid \\
\hline 1 & Biaya awal (initial cost) & 93.243 .462 .000 & 95.737 .231 .000 & 93.069 .528 .000 \\
\hline 2 & Biaya Pemeliharaan & & & 9.887 .299 .482 \\
\hline & Rutin & 9.887 .299 .482 & $5.579 .457 .942,61$ & 25.530 .692 .115 \\
\hline & Berkala & 14.734 .539 .482 & 14.304 .626 .806 & 35.417 .991 .597 \\
\hline & $\begin{array}{l}\text { Total Biaya pemeliharaan } \\
\text { (Maintenance cost) }\end{array}$ & 24.621 .838 .964 & 19.902 .084 .749 & 0 \\
\hline 3 & Salvage cost & 0 & & 0 \\
\hline 4 & Life cycle cost & 120.865 .300 .964 & 115.639 .315 .749 & 128.487 .519 .597 \\
\hline 5 & Saving cost (Existing-Alt.) & 7.662 .218 .633 & 12.848 .203 .849 & 0 \\
\hline
\end{tabular}




\section{Tahap Rekomendasi (Recommendation Phase)}

Tahap rekomendasi merupakan tahap akhir dari keseluruhan langkah-langkah aplikasi Rekayasa Nilai (value Engineering). Dalam tahap ini disebut juga pengembangan dan penyajian. Dari Tabel 10, dapat dilihat kelebihan metode konstruksi CAM

Terpilih dibandingkan dengan metode konstruksi geotextile dan geogrid kombinasi cerucuk (existing) dan VVD dan HSD terletak pada biaya pemeliharaan (C) yang lebih kecil dan ekonomis dapat dilihat pada Tabel 11 :

Tabel 11 Kelebihan dan Kekurangan Alternatif Yang Terpilih

\begin{tabular}{|c|c|c|c|c|}
\hline \multirow[b]{2}{*}{ NO } & \multirow[b]{2}{*}{ Alternatif } & \multicolumn{3}{|c|}{ Alternatif Metode Konstruksi } \\
\hline & & Alternatif Existing (1) & Alternatif VVD dan HSD (2) & $\begin{array}{c}\text { Alternatif CAM (3) } \\
\text { terpilih } \\
\end{array}$ \\
\hline & & Kurang & Unggul & Unggul \\
\hline 1 & Mutu Konstruksi (A) & $\begin{array}{c}\text { Lebih cepat rusak } \\
\text { dibandingkan altrnatif } \\
2,3\end{array}$ & Lebih baik dari alt 1 . & Lebih baik dari alt 1.2 \\
\hline & & Unggul & Kurang & Kurang \\
\hline 2 & Biaya awal (B) & $\begin{array}{c}\text { Lebih murah } \\
\text { dibandingkan alt 2, } 3\end{array}$ & Lebih mahal dari alt. 1,3 & \\
\hline & & 93.069 .528 .000 & 96.243 .462 .000 & 95.737 .231 .000 \\
\hline & & Kurang & Kurang & Unggul \\
\hline 3 & Biaya pemeliharaan $(\mathrm{C})$ & $\begin{array}{c}\text { Biaya pemeliharaan } \\
\text { lebih besar dibanding } \\
\text { alt. } 2,3\end{array}$ & $\begin{array}{c}\text { Biaya pemeliharaan lebih besar } \\
\text { dibanding alt. } 3\end{array}$ & $\begin{array}{c}\text { Biaya pemeliharaan } \\
\text { lebih kecil dari alt. } 1,2\end{array}$ \\
\hline & & 35.417 .991 .597 & 24.621 .838 .964 & 19.902 .084 .749 \\
\hline & & Kurang & Unggul & Unggul \\
\hline 4 & Ramah lingkungan $(\mathrm{F})$ & $\begin{array}{c}\text { Tidak ramah } \\
\text { lingkungan karena } \\
\text { menggunakan cerucuk } \\
\text { kayu }\end{array}$ & Ramah lingkungan & Ramah lingkungan \\
\hline & & Kurang & Unggul & Unggul \\
\hline 5 & Teknologi ( I) & $\begin{array}{c}\text { kurang dibandingkan } \\
\text { alt. } 2,3\end{array}$ & Lebih baik dari alt 1 . & Lebih baik dari alt 1 \\
\hline
\end{tabular}

\section{KESIMPULAN DAN SARAN}

\section{Kesimpulan}

1. Berdasarkan hasil analisis diagram Pareto, pelaksanaan pekerjaan asphalt dan selected embankment berpotensi untuk dilakukan aplikasi analisis Rekayasa Nilai

2. Berdasarkan analisis matriks metode Zero-one alternatif metode Cakar Ayam Modifikasi (CAM) memiliki nilai preferensi lebih baik yaitu 64,46, dibandingkan dengan alternatif VVD dan HSD yang memiliki bobot 56,66 serta existing yang memiliki bobot 43,36 .

3. Penghematan biaya (Cost saving) setelah dilakukan aplikasi Rekayasa Nilai (Value Engineering) sebesar 12.848.203.849,39,- atau 10\% untuk pelaksanaan konstruksi dengan metode dan teknologi konstruksi

Cakar

Ayam

Modifikasi

(CAM). 


\section{Saran}

1. Penerapan rekayasa nilai sebaiknya dilaksanakan pada tahap desain sehingga diperoleh penghematan sesuai tujuan dari penerapan metode tersebut.

2. Sebaiknya rekayasa nilai (value engineering) dibudayakan dengan kendali yang baik, sehingga tidak terjadi pemborosan yang terselubung.

3. Sebaiknya VE dilakukan oleh tim dari berbagai disiplin ilmu agar hasil yang didapatkan lebih maksimal.

\section{UCAPAN TERIMA KASIH}

Penulis mengucapkan terima kasih kepada pihak yang telah memberi dukungan financial terhadap penelitian ini

\section{DAFTAR PUSTAKA}

Dell'Isola, AJ 1975, Value Engineering in The Construction Industry Van Nostrad Reinhold, New York.

Marzuki, PF 2007, Makalah Rekayasa Nilai : Konsep dan Penerapannya di dalam Industri Konstruksi, Institut Teknologi Bandung.

Peraturan Menteri Pekerjaan Umum Nomor 13/PRT/M/2011tentang Tata Cara Pemeliharaan Jalan dan Penilikan Jalan.

Peraturan Menteri Pekerjaan Umum Nomor 06/PRT/M/2008, Pedoman Pengawasan Penyelenggaraan Pelaksanaan Pemeriksaan Konstruksi Di Lingkungan Departemen Pekerjaan Uтит.

Pradana, RJ 2007, Teknik Optimasi, viewed, 17 November 2012, Available from internet <http//ajaka multiply.com//journal/item/6>.

Saptono 2008, Analisis Penentuan Bangunan Atas Jembatan Dengan Metode Rekayasa Nilai studi kasus pada jembatan KaliPacangan Kecamatan Kejobong Purbalingga, Universitas Islam Indonesia Yogjakarta.

World Bank 2013, Bagaimana tingkat bunga Bank Dunia dibandingkan dengan sumber pembiayaan pemerintah lainnya, Viewed 23 April 2012, <http://web.worldbank.org>.

WVDOH Ofice Service Division 2004, Value Engineering Manual. West Virginia Department of Transportation.

Widodo, RA 2007, Aplikasi Value Engineering Terhadap Struktur Balok dan Pondasi Untuk Biaya Proyek Pembangunan Kantor Perpustakaan Daerah Provinsi Jawa Tengah. Universitas Negeri Semarang, Semarang, Jawa Tengah.

Wilson, DC 2005, NCHRP Synthesis 352: "Value Engineering Applications in Transportation”, A Synthesis of Highway Practice, Transportation Research Board, Washington D.C.Transportation Research

Board, Washington

D.C. 
Widono,W 2002, Optimasi Pemilihan Jenis Material untuk Struktur Kuda-Kuda Dengan Metode Rekayasa Nilai, Universitas Islam Indonesia, Yogjakarta.

Zimmerman, LW \& Hart, GD 1982, Value Engineering A Practical Approach for Owners, Designers, and Contractors, Van Nostrand Reinhold Company, New York. 